\title{
Brief Discussion on Middle School Class Teacher Education Management Method
}

\author{
Sun Jingsheng ${ }^{1}$, Li Cheng ${ }^{1}$, Wang Guanglie ${ }^{2}$ \\ ${ }^{1}$ Zhenlai County Third Middle School, Jilin Province, China \\ ${ }^{2}$ Zhenlai County Second Middle School, Jilin Province, China \\ sjszhenlai@163.com
}

\begin{abstract}
Middle school is critical period of student growth. During this period, the class teacher plays multiple roles, which includes a good class organizer, education administrators and psychological growth guide. How to find the right entry point, and promote the psychological development of middle school students through class management, that is very important for the comprehensive development of middle school students. Aiming at the difficult problems appeared in middle school class management, this paper studied middle school teacher class management and effective measures should be taken.
\end{abstract}

Index Terms - class teacher, education management, difficult problems, student-centered

\section{Introduction}

Middle school education, which is the highest level secondary education in the current education system of our country, plays an important role of student election and transporting for the college. Middle school is key stage, when student develops creative ability, hobbies and self-learning ability, and students' plasticity is stronger.

Compare with high-quality school students, mostly general middle school students have weak cultural foundation, and not good study habits. Their organization and discipline lax, nonlearning content more social activities, self-regulatory capacity is weak. These features of the general middle school students lead to difficult of their ideological education. School should pay more energy, more refined methods and greater education efforts to middle school students than the high-quality school. According to middle school stage education training objectives, promote the comprehensive development and healthy growth of these students. Therefore, for the general middle school, starting from the student ideological education, improving the student ideological level and management level, promoting student education and development, this is very important.

As a coordinator, organizer and leader of the teaching work, class teacher play an important role in student's elementary education, life and values culture. How to strengthen the middle school class teacher management level, that has become a hot topic of China education field. Directed to the existing management difficulties, Teacher should be student-oriented, good class management, thus shaping students' good character and become talents.

\section{Difficult Issues Analysis of Class Teacher Work Management}

\section{A. Middle school adolescent rebellion serious, and management difficulties increase}

Middle school students are in a period of rapid development, and their psychological develop from naive to mature gradually. In this period, most students showed desire for independence, be able to actively express their views. But there is no formation of a correct outlook on life and values. Therefore, middle school students prone to extreme psychological and often show treason, rebellion, that leads middle school class teacher difficult to carry out the management [1].

\section{B. Mental weariness obvious, self-learning ability is not strong}

Since middle school learning environment, curriculum difficulties and the life pace are larger difference from primary school and there are heavier burden on student. So it is easy for students to have a strong aversion to learning, coupled with a serious rebellion. If improper discipline, it is easy to cause improper deletion learning objectives, self-learning ability of adverse consequences.

\section{Lack of collective concepts and teamwork consciousness}

Most students are the only child at present, when they get along with the class teacher and classmates, often consider from the personal point of view, lack of awareness on collectivism, there is no sense of teamwork. Therefore, the class teacher's management work is not easy to carry out, and the student is not strong spirit of collaboration [2].

D. Part of teacher and parents focus on scores too much and ignoring the overall development of students

Forced by personnel selection system now, there are many teacher and parents measure student by test scores. They ignore the care and guidance of students and combat students' self-respect. Such ideas and practices not conducive to the formation of students' sound personality and education work. The class teacher should pay more attention to this regard, and do more work [3]. 


\section{Student-Centered, Take Positive and Effective Class Management Measures}

\section{A. Change the educational philosophy and strategy}

In the traditional philosophy of education, the class teacher's authority is not violated, and students can only obey. At this stage, middle school class teacher should update class management concepts, and establish the "people-oriented" concept. The emotions of service, care and trust in the students are merged into class management work, changing the traditional "feeding style" management concept, and establishing a student-centered educational philosophy. Sukhomlinski said: "Teachers love children are the most important things in their life." Class teacher should establish the job based on the care, love and trust in students, so that students respect and trust the class teacher, they are willing to accept teacher education and management. Middle school students are in rebellion, so class teacher should take care of them initiatively, rather than the authority to suppress. This can enhance the sense of more students trust, and students will actively cooperate with the teacher's management [4].

Meanwhile, promote management work by quality education. The traditional examination-oriented education measure student learning outcomes by test scores, which leading to middle school mentality is twisted. The class teacher must unswervingly implement quality education, and promote the overall development of students' comprehensive ability to enable students to grow up healthy.

\section{B. Implement management of firmness and flexibility, training student's self-management skills}

Currently, it is a common phenomenon, that middle school students late, leave early and do not obey teachers manage. Therefore, appropriate criticism and punishment should first be given for such students. However, students should be enable to understand their strengths clearly in this process, and their academic performance should be affirmed, the student's attention are introduced into their areas of expertise. The management of firmness and flexibility approach is used to promote overall development of students, not be too loose or too constricting. The class teacher managed to grasp the "degree", so as to solve the management problems, to promote the healthy development of students in all directions.

Middle school is the most obvious stages of students' selfdevelopment, the class teacher should change the previous method of class rules and constraints, bold decentralization to the students to enhance their self-management skills, to develop their initiative and enthusiasm, to cultivate outstanding class leadership groups, so that they become the backbone of the class and the class teacher's assistant, rather than just between teacher and student mouthpiece.

\section{Create a class disciplinary system and build efficient class committee}

Discipline is the premise of management, in order to achieve effective management of the entire class, it is necessary to develop scientific and strict disciplinary system by the class teacher. Class discipline system should comply with the law of student thinking and development. Only such a system is the scientific, human system. When the class teacher make the class management discipline, it must go close to the people route, never dogmatic and arbitrary. Seeking the views of students is the best way to achieve the people first line, let student give advice and suggestions for the class management, and actively participate in class construction.

Let the students in the class are aware of the seriousness of discipline, and every student must be disciplined. Only really student aware of the class discipline importance, the effective management is truly achieved. Through the various class activities that organized by teacher, train students' collective sense of honor, responsibility, and strengthen the collective consciousness of the students, in order to carry out class management better [5].

Class committee election is the core of the class management, and class committee is a student selfmanagement body. Building efficient class committee helps to manage students scientifically and efficiently. When class committee in building, the elections of the democracy principles should be upheld, and according to the number of votes to select the class cadre. In the selection process of class cadres, the class teacher should choose the best students as class cadre, it can be beneficial to carry out their work.

\section{Application talking art, strengthen the communication between teachers and students}

Middle school students are in the transition of youth to young adolescent period, their mental and physical development is gradually maturing, personality psychology have the degree of independence and autonomy, prone to acts of rebellion and. Therefore, class teacher must strengthen communicate with students. Only through appropriate communication means, class teacher could into the student's soul and know what they are thinking.

Each student's heart is very eager to get the teacher's appreciation and recognition. Therefore, the class teacher must make full use of the psychological characteristics of students, use language motivational strategies flexibly, and motivate the students appreciated in a right time. When student make achievements and progress bit by bit, he should receive timely, sincere verbal promise and encouragement. Meanwhile, the teacher could also inform student parents these advances timely, so parents can take part in and strengthen these appreciation incentives. This incentive strategy, not only strengthen the students' confidence and enhance the students' learning motivation, but also contribute to the formation of the class members starting a good style of study, and class atmosphere.

Communication method is ingenious applied and achieve effective communication between teachers and students, which include praise art, criticism artistic strategies and talk strategy. At the same time, teachers should summarize experience 
constantly, and improve the students' communication arts continuously.

\section{E. Strengthening the construction of students' mental health}

Psychologists believe that the middle school stage is "psychological weaning period" of individual development. This stage is at the crossroads of life. On the one hand, this stage is a period of rapid changes in the ideal and faith. Values, outlook on life, and world outlook develop from germination to form. It is a starting point of guiding themselves with moral consciousness and concept. On the other hand, this stage is adolescence, which physiological matures quickly, and psychological development can't keep up with the physical development. They are prone to subjective and one-sided understanding. Their mood and emotion are growing but not stable. It's easy to have a poor self-control, reverse and hostile psychology.

As a special social group, middle school students are in the midst of a transition from psychological immature to mature. At the same time, school and family tend to attaches great importance to the study result, and ignore the law of student development. This adding to the middle school student's psychological contradictions and conflicts, and make the students psychological behaviour problems increasing, which will seriously affected the healthy development of student's body and mind.

The so-called mental health construction mainly refers to the middle school students are educated and counseled in areas such as physical and mental maturity, life, world outlook and values. Student's ability of anti-frustration and to overcome difficulties is trained. Their physical and mental development and mental maturity are promoted. During class management, the mental health building elements include: Chinese traditional virtues education, overcome bad habits, actively communicate with their parents, develop anti-strike capability, and handle the relationship between learning and entertainment correctly, normal intercourse with the opposite and so on. Only by strengthening the construction of mental health of students, students can form a strong mental capacity, correctly deal with every thing [6].

\section{F. Individualized, focus on student's personality development}

Based on full knowledge of the students' psychological conditions, the class teacher should individualize according to the different circumstances of each student, and train students' personality. Some students have set a very strong sense of the ideal, if this ideal itself is positive, then the class teacher should pay attention to encouraged him regularly to adhere to his ideals and unremitting effort. Some students set impractical ideals, facing this kind of students, the class teacher should use role models cleverly, help them choose more practical, positive and realistic goals. While most students are not strong sense of the ideal, facing this kind of students, the class teacher should not be excessive intervention, and help students explore their own potential by way of encouragement.
Students' personality is most apparent during the middle school period. The class teachers should training diversified management methods in the management work, get rid of unified management, respect and care for the student's personality in managing work, pay attention to students personality development in their daily teaching management, maintain the attitude of encouragement and support for students. These methods could stimulate students' potential awareness, and achieve the purpose of guiding the student's personality scientifically.

Meanwhile, the class teacher should also analyze student thinking differences of gender and individual from a psychological point of view. Let students understand themselves ability and characteristics from a theoretical point of view, and carry out the activities actively that foster students' self-confidence.

The class teacher should think frequently and good at summing up education and management opportunities. So they will be able to work more smoothly. When teacher encounter problems, they should doing self-reflection firstly, and then analyze the specific situation. Before the specific class management action, the teacher should carefully distinguish individual differences of students, and can use the scientific method of education and management to guide students to learn better, thereby receiving better education and management effectiveness.

\section{G. Establish an effective communication mechanism with the students and their parents}

In the class management process, the class teachers should closer the relationship with students and their parents, and establish an effective communication mechanism with them. Thereby enhancing the understanding of the students' psychological trends, and the various problems encountered in the process of learning can be feedback to parents timely. So their parents could work with the school to help students solve problems. Treat students, the class teacher should carry out general mental communication as a friend, earning the trust of students. Treat parents, the teacher should communicate with them regularly, in order to detect the problems of students, and find the best way to solve the problem. When the class teacher is communicating with parents, they need to pay attention to ways and means.

\section{Conclusions}

In summary, the class teacher as a model student learning and working, they will impact the student future development directly. Middle school class teacher class management is a dynamic and systematic process, and it requires the continuous efforts of the class teacher to make progress in this process. In middle school education and teaching, how to strengthen the class management, it need long-term explore and study. Class teacher work is a complex task, we only have to start from scratch, from the trivial, capitalize on the trend, give students more humane care, and get the job done to the hearts of the 
students. In order to offers students the best quality education, and create the best opportunities for their future.

\section{References}

[1] Wan Guipeng. On the Management of the Education. Science Mosaic, 2005 (11)

[2] Zou Derui. Class Advisor Management Strategies Research. The Science Education Article Cultures, 2013 (8)
[3] TIAN Hongbo. Classroom Management in High School Education. Open Class Teachers' Version, 2010 (3)

[4] Xie Lingqun. Research on Middle School Management in the Background of Quality Education. The Science Education Article Cultures, 2013 (17)

[5] Hu Lingxia. Some thoughts on the humanistic management in school education management. Journal of Jiamusi Education Institute, 2013 (7)

[6] Wang Xianfeng. A Brief Discussion on Effective Class Management. The Science Education Article Cultures, 2013 (24) 